\title{
Targeting the Clot in Acute Stroke
}

$\mathbf{R}^{\mathrm{e}}$ ecent stroke trials have undeniably shown that thrombectomy is not just a safe method for treating acute stroke but also can extend the accepted time window considerably. ${ }^{1,2}$ While most imaging techniques have rightly focused on first detecting hemorrhage or other sources of potential stroke mimics or the eventuality of cerebral hypoperfusion amenable to restoration through vascular techniques, very little research has focused on the thrombus itself. This is strange because it is the thrombus that has been the target of both pharmaceutical and interventional therapies because it is known to be the cause of the event. Imaging techniques such as CT perfusion and MR perfusion readily document the presence or absence of areas of perturbed perfusion that may be larger or smaller than expected, but these techniques would require a successful neuroprotective agent to fulfill their promises as techniques for full revascularization.

Currently, imaging needs to just demonstrate the absence of a hemorrhagic event and the presence of a clot for a decision to proceed to the angiography room. While the large-scale implementation of clot extraction using interventional techniques has allowed major advances with major improvement in clinical outcomes with fewer hemorrhages, selecting the right device for the right occlusion type will play a more important role. On the one hand, as has been the case with aneurysm treatment-planning, probably the clot location and thus its orientation will have an impact on the choice of catheters; it is also possible that looking at the clot itself and trying to deduce its composition could be helpful for deciding which patients undergo which therapy. Indeed, if a clot is more calcific, more fibrinous, or contains more blood cells, the management types may differ because the consistency will have an impact on retrieval and eventually on distal migration that might occur during the procedure. While in vitro studies may indeed be helpful to determine clot composition, determining the exact morphology and consistency of the clot will be necessary.

Indeed, some data are also available for MR imaging with the susceptibility vessel sign, ${ }^{3}$ which demonstrates high erythrocyte content. Using modern CT techniques may be a way to further characterize these clots: Indeed, CT is, currently, the preferred technique of choice for the first evaluation of a patient with stroke, due to its sensitivity for hemorrhage. ${ }^{4}$ The dense artery sign is a well-established sign of acute occlusion that corresponds to the presence of an occluding clot. The morphology and direction of the clot and the associated vessel morphology can be assessed by CTA; however, more exact information on clot composition might be extracted by further evaluation of the imaging characteristics of the clot. ${ }^{5,6}$ Indeed, relatively simple measures of density could be helpful, but it may be difficult to differentiate high density due to red blood hemoglobin content from calcific changes. Therefore, additional measurements such as postcontrast images to assess eventual porosity or investigate calcification with dual-energy CT could quickly provide additional findings to help show clot composition that would guide an improved choice for thrombectomy-device selection. As with any imaging technique chosen to assess stroke, this will only provide another part of the information needed and is not a solution but could provide insight into clot composition to guide therapy. Also, as with most other imaging techniques, it should not interfere by prolonging unnecessary imaging time and thus time to therapeutic decision.

\section{REFERENCES}

1. Jovin TG, Chamorro A, Cobo E, et al; REVASCAT Trial Investigators. Thrombectomy within $\mathbf{8}$ hours after symptom onset in ischemic stroke. N Engl J Med 2015;372:2296-306 CrossRef Medline

2. Nogueira RG, Jadhav AP, Haussen DC, et al; DAWN Trial Investigators. Thrombectomy $\mathbf{6}$ to 24 hours after stroke with a mismatch between deficit and infarct. $N$ Engl J Med 2018;378:11-21 CrossRef Medline

3. Liu H, Mei W, Huang Y, et al. Susceptibility vessel sign predicts poor clinical outcome for acute stroke patients untreated by thrombolysis. Exp Ther Med 2017;14:5207-13 CrossRef Medline

4. Bouchez L, Sztajzel R, Vargas MI, et al. CT imaging selection in acute stroke. Eur J Radiol 2017;96:153-61 CrossRef Medline

5. Bouchez L, Lovblad KO, Kulcsar Z. Pretherapeutic characterization of the clot in acute stroke. J Neuroradiol 2016;43:163-66 CrossRef Medline

6. Bouchez L, Altrichter S, Pellaton A, et al. Can clot density predict recanalization in acute ischemic stroke treated with intravenous tPA? Clinical and Translational Neuroscience 2017;1:1-6 CrossRef

(D) K.-O. Lövblad

Division of Diagnostic and Interventional Neuroradiology Geneva University Hospitals Geneva, Switzerland 